\title{
MORFO-ANATOMIA E ASPECTOS DA BIOLOGIA FLORAL DE NECTANDRA MEGAPOTAMICA (SPRENG.) MEZ (LAURACEAE) ${ }^{1}$
}

\author{
Luiz Antonio de Souza ${ }^{2}$ \\ Ismar Sebastião Moscheta ${ }^{2}$
}

Recebido em 30/03/1999. Aceito em 25/11/1999

\begin{abstract}
RESUMO - (Morfo-anatomia e aspectos da biologia floral de Nectandra megapotamica (Spreng.) Mez (Lauraceae)). Nectandra megapotamica (Spreng.) Mez é espécie freqüente nas matas secundárias da região de Maringá, Estado do Paraná, Brasil. A morfologia e estrutura de suas flores, bem como observações da antese, deiscência das anteras, receptividade do estigma e do registro de insetos visitantes são objetos do trabalho. A antese é diurna e as anteras só se abrem no segundo dia, quando o estigma não é mais receptivo. O comportamento da flor caracteriza a ocorrência de dicogamia. O inseto visitante mais freqüente pertence à Thysanoptera. As tépalas têm epiderme simples, com pêlos tectores e glandulares e complexos estomáticos paracíticos, e mesofilo parenquimático homogêneo. Os nectários têm parênquima secretor com tecido vascular apresentando predominância de floema. As anteras possuem epiderme unisseriada pilosa, endotécio, duas ou três camadas médias e tapete com células binucleadas. $\mathrm{O}$ estigma apresenta pêlos multicelulares unisseriados. $O$ ovário possui epiderme glabra, parênquima com atividade meristemática subepidérmica e fenda como região sutural vestigial. O único óvulo é pêndulo, anátropo e bitegumentado.
\end{abstract}

Palavras-chave - Nectandra megapotamica, anatomia floral, antese, dicogamia, Lauraceae

ABSTRACT - (Morphology, anatomy and floral biology of Nectandra megapotamica (Spreng.) Mez (Lauraceae)). Nectandra megapotamica (Spreng.) Mez is a common species in secondary forests of the area of Maringá, the State of Paraná, Brazil. The morphology and structures of its flowers and observations of anthesis, dehiscence of anthers, receptivity of the stigma and insect visitor registration are the objects of this investigation. Anthesis is diurnal and anthers only dehisce during the second day, when the stigma is not anymore receptive, characterizing dichogamy. The most frequent insect visitor were thrips (Order Thysanoptera). The tepals have a simple epidermis, with nonglandular and glandular hairs and paracytic stomata, and homogeneous parenchymatous mesophyll. Nectaries have secretory parenchyma, with vascular tissue, constituted mainly of phloem. The anthers possess a uniseriate hairy epidermis, endothecium, two or three middle layers and a tapetum with binucleate cells. The stigma presents multicellular uniseriate hairs. The ovary has a glabrous epidermis, a parenchyma with subepidermical meristematic activity and a rift as the vestigial sutural area. The single ovule is pendulous, anatropous and bitegmic.

Key words - Nectandra megapotamica, floral anatomy, anthesis, dichogamy, Lauraceae

Departamento de Biologia, Centro de Ciências Biológicas, UEM, CEP 87020-900, Maringá, PR, Brasil 


\section{Introdução}

As espécies arbóreas com potencial econômico e/ou ecológico, ocorrentes em remanescentes florestais, são cada vez mais importantes no atual cenário de redução da cobertura florestal acarretado pela ocupação agrícola. Na região noroeste do Estado do Paraná, o processo de utilização de terras por culturas vegetais reduziu a menos de $1 \%$ a área de florestas. Estudos da biologia reprodutiva dessas plantas permitem subsidiar o seu uso para manutenção e recuperação de áreas perturbadas. A morfologia e a biologia floral são conhecimentos básicos para o entendimento do seu processo de reprodução.

Dentre as espécies que ainda restam, muitas ameaçadas de extinção, ocorre Nectandra megapotamica, da família Lauraceae, conhecida vulgarmente como canela-fedorenta, canelinha ou canela-amarela, de hábito arbóreo, ciófila e fitossociologicamente importante. Essa espécie é considerada como pertencente ao estádio sucessional secundário inicial. Sua madeira pode ser utilizada em qualquer aplicação de construções civis e navais. Essa planta pode ser utilizada, também, para recomposição de matas ciliares, para o adensamento ou enriquecimento florestal em capoeirões, florestas exploradas ou devastadas (Reitz et al. 1983; Rodrigues et al. 1992).

Os estudos de morfologia e biologia floral de espécies de Lauraceae são registrados por Kostermans (1957), Kubitzki \& Renner (1982), Kubitzki \& Kurz (1984), Lloyd \& Webb (1986), Bertin \& Newman (1993) e em trabalhos mais recentes de Endress \& Igersheim (1997) e Gibson \& Diggle (1998).

A necessidade do desenvolvimento de estudos biológicos com espécies de mata, ambiente cada vez mais raro no Paraná e no Brasil, principalmente aqueles alusivos às suas estruturas reprodutivas, motivou a realização do presente trabalho com Nectandra megapotamica, cujas flores foram investigadas morfo-anatomicamente. Algumas observações de campo, referentes à antese e à polinização, complementaram o referido estudo.

\section{Material e métodos}

O Horto Florestal de Maringá, local de ocorrência e de coleta de Nectandra megapotamica (Spreng.) Mez, abrange um área de 37 hectares e situa-se entre os meridianos $51^{\circ} 30^{\prime}$ e $54^{\circ} \mathrm{W}$ e os paralelos $22^{\circ} 30^{\prime}$ e $24^{\circ} 30^{\prime}$ 'S, em altitude média de $556 \mathrm{~m}$. Inicialmente, foram marcados dois exemplares da espécie que serviram para coleta e observações. O material botânico coletado consistiu em botões florais e flores, além de ramos para montagem de exsicata, depositada no Herbário da Universidade Estadual de Maringá (HUM 1113) e utilizada para identificação da espécie.

A análise da estrutura floral do material botânico foi feita em material fresco ou fixado, em solução de álcool etílico $50 \%$, ácido acético glacial e formaldeído (FAA 50) ou de álcool etílico $50 \%$, ácido propiônico e formaldeído (FPA 50) (Johansen 1940). As lâminas semipermanentes e permanentes para os estudos microscópicos foram preparadas segundo técnicas usuais (Johansen 1940; Dnyansagar 1958). Os ovários e tépalas foram analisados em material diafanizado (Herr 1971). Foram realizados testes para celulose, amido, lignina, mucilagem e lipídio, utilizando-se corantes ou reagentes específicos (Johansen 1940; Rawlins \& Takahashi 1952; Berlyn \& Mikshe 1976).

As observações das flores no campo foram feitas no período de agosto a setembro/1988. Foram marcados botões florais para observação diária necessária à caracterização do processo de antese, do horário e do tipo de deiscência das anteras, do período de receptividade do estigma e da senescência das tépalas e estames. $\mathrm{O}$ registro da visita de insetos às flores foi feito no decorrer de um dia, sendo os mesmos coletados e, posteriormente, identificados. Essas observações foram feitas sob temperatura atmosférica média de $16,2^{\circ} \mathrm{C}$ e umidade relativa média de $33 \%$.

Os desenhos e diagramas foram elaborados 
com o auxílio de câmara-clara projetando-se, nas mesmas condições ópticas, a escala micrométrica correspondente.

\section{Resultados}

Morfologia e antese - A floração ocorre durante os meses de julho a setembro. As flores são brancas a amarelas, diminutas e monoclinas e dispõem-se em inflorescências complexas que se sobressaem na copa verde da planta. A inflorescência, tipo panícula, é formada por um eixo principal que se ramifica em eixos secundários e terciários, ao longo dos quais ocorrem pequenos ramos florais tripartidos (tríades), bipartidos ou raramente simples.

Os pequenos botões florais, pilosos, desenvolvem-se na axila de uma reduzida bráctea verde. Nos pedúnculos destes botões ocorre uma pequena bractéola. O perigônio fechado é constituído de três tépalas externas que recobrem as três mais internas (Fig. 1-2). Os seis nectários de cor amarela são curtamente pedunculados e ocorrem entre os verticilos externo e interno de estames (Fig. 3). O androceu é constituído por nove estames férteis e três estaminódios ovóides; os seis estames mais externos são introrsos e adnatos às tépalas pelo reduzido pedúnculo; os três internos, alternados com os estaminódios, envolvem lateralmente o estigma e têm anteras extrorsas (Fig. 3-4); os estaminódios são curtamente pedicelados. O gineceu (Fig. 15-21) apresenta ovário unicarpelar, globoso e glabro.

A antese ocorre em horário variável do dia e, uma vez iniciada, pode prolongar-se por um ou dois dias. O processo inicia-se pela flor central da tríade e caracteriza-se pelo afastamento de apenas uma tépala. Em seguida, as outras tépalas dos verticilos externo e interno abremse, assumindo a posição vertical. Desse modo, o estigma e os estames são expostos, permanecendo estes com as anteras fechadas e justapostas. Em seqüência, as tépalas se tornam horizontais ou oblíquas em relação ao eixo floral, levando consigo os estames dos verticilos externos que são adnatos às tépalas. Com o afasta- mento dos estames, os nectários tornam-se visíveis. As anteras só se abrem no segundo dia após a antese, quando geralmente o estigma já iniciou o processo de senescência, observado pelo escurecimento de suas papilas (Fig. 1-4).

As flores foram visitadas por insetos pertencentes às Ordens Thysanoptera e em menor grau, Diptera e Hymenoptera.

Tépalas - As tépalas são estruturalmente simples (Fig. 5), sendo constituídas de epiderme unisseriada e cuticularizada e mesofilo parenquimático homogêneo (Fig. 6). Na face abaxial da epiderme ocorrem pêlos tectores (Fig. 7), uni ou pluricelulares, de extremidade afilada e paredes espessas. Na face adaxial, além dos pêlos tectores, observam-se na epiderme outros mais abundantes, os glandulares e multicelulares (Fig. 9). Os complexos estomáticos paracíticos só foram notados na superfície abaxial da epiderme (Fig. 7). No bordo da tépala o mesofilo reduz-se a um único estrato celular e a epiderme é caracterizada pela presença de tricomas pluricelulares (Fig. 8). A vascularização da tépala é feita por três ou quatro feixes colaterais (Fig. 5).

Nectários - Os nectários possuem epiderme unisseriada, glabra, de células de paredes delgadas. O tecido secretor de natureza parenquimática é formado por células diminutas, poliédricas, nucleadas e densamente citoplasmáticas. Nesse parênquima ocorrem amplas células oleíferas (Fig.10). Os nectários são vascularizados por xilema e, predominantemente, floema.

Estames - Nas flores em pré-antese, as anteras são tetraesporangiadas e, quando jovens, apresentam a valva constituída de epiderme simples com células pouco vacuolizadas, o tecido precursor do endotécio, dois ou três estratos médios de células tabulares e o tapete do tipo secretor com células amplas, de abundante citoplasma e binucleadas (Fig. 11). Em fase mais adiantada de desenvolvimento, a antera apresen- 
ta-se com epiderme papilosa e com tricomas de duas ou três células, o endotécio com células amplas, mas de paredes delgadas, e o tapete e um estrato de camada média desorganizados (Fig. 12). Nas flores em antese as anteras têm deiscência valvar (Fig. 4). Cada valva apresenta apenas epiderme e endotécio, com espessamento secundário nas paredes celulares periclinais internas e anticlinais, enquanto os demais estratos celulares se desorganizam (Fig. 13-14). A vascularização da antera é feita por um único feixe colateral (Fig. 13).

Gineceu - O estigma apresenta pêlos epidérmicos multicelulares unisseriados, de formato alongado, com células vacuoladas, nucleadas e de paredes delgadas (Fig. 16). O contato destes pêlos com o tecido transmissor do estilete faz-se através do deslocamento gradativo deste tecido em direção à epiderme, $\mathrm{o}$ que ocorre na região apical do estilete. Não se constatou secreção abundante na superfície do estigma, caracterizando-o como seco.

O estilete é reduzido (Fig. 15) e sólido (Fig. 18), apresentando epiderme cuticularizada, de células prismáticas com paredes periclinais espessas, que revestem o tecido parenquimático (Fig. 19). Imersos neste parênquima, observamse o tecido transmissor (Fig. 18-19) e o único feixe vascular (Fig. 18) colateral. O tecido transmisssor percorre todo o estilete atingindo o funículo, tornando possível o desenvolvimento do tubo polínico desde o estigma até o rudimento seminal.

$\mathrm{O}$ ovário é formado por epiderme externa simples, cuticularizada e glabra. O mesofilo é parenquimático, onde se destacam amplas células oleíferas (Fig. 20). As camadas de células do mesofilo, subjacentes à epiderme interna, sofrem divisões periclinais e posterior alongamento tangencial (Fig. 20). A região sutural do carpelo é vestigial e destaca-se na superfície do ovário e ao longo do estilete, como uma fenda (Fig. 15) que atravessa toda a parede ovariana (Fig. 17).
A vascularização do gineceu é feita na base do ovário por vários feixes, alguns ainda com células procambiais, que se reúnem em apenas dois feixes colaterais na região placentária. Um desses feixes penetra no funículo e o outro vasculariza o estilete e a base do estigma.

O único rudimento seminal é pêndulo, anátropo, bitegumentado (Fig. 21-22) e com várias camadas celulares entre a epiderme nucelar e o saco embrionário (Fig. 23). O tegumento externo é formado por epiderme e parênquima multisseriado; o tegumento interno tem poucos estratos celulares e mostra na região apical células mais volumosas (Fig. 23). O nucelo é parenquimático com evidências de divisões celulares periclinais. Foi observado apenas o aparelho oosférico, com as duas sinérgides e a oosfera (Fig. 23). A vascularização do rudimento seminal é feita por apenas um feixe colateral (Fig. 21-22).

Flor em pós-antese - Após o período de receptividade do estigma e a abertura das anteras, verifica-se o processo gradual de senescência das tépalas, nectários e estames, que ocorre entre o terceiro e o quinto dia, completando-se em torno do sexto dia após a antese. Posteriormente ocorre a queda destas estruturas secas, expondo o pequeno fruto verde envolvido pela cúpula.

\section{Discussão}

As observações sobre a antese de $N$. megapotamica mostraram que as anteras e os estigmas são expostos simultaneamente, mas as anteras só se abrem no segundo dia após a ocorrência do fenômeno, quando o estigma já não é mais receptivo. O comportamento da flor caracteriza a ocorrência de dicogamia (protoginia). Essa dicogamia intrafloral, segundo Lloyd \& Webb (1986), pode aumentar a probabilidade de polinização cruzada, muito embora Faegri \& Pijl (1971) afirmem que pode ocorrer autopolinização entre flores de diferentes estádios no mesmo indivíduo. A dicogamia, já registrada em outras espécies neotropicais de Lauraceae por 

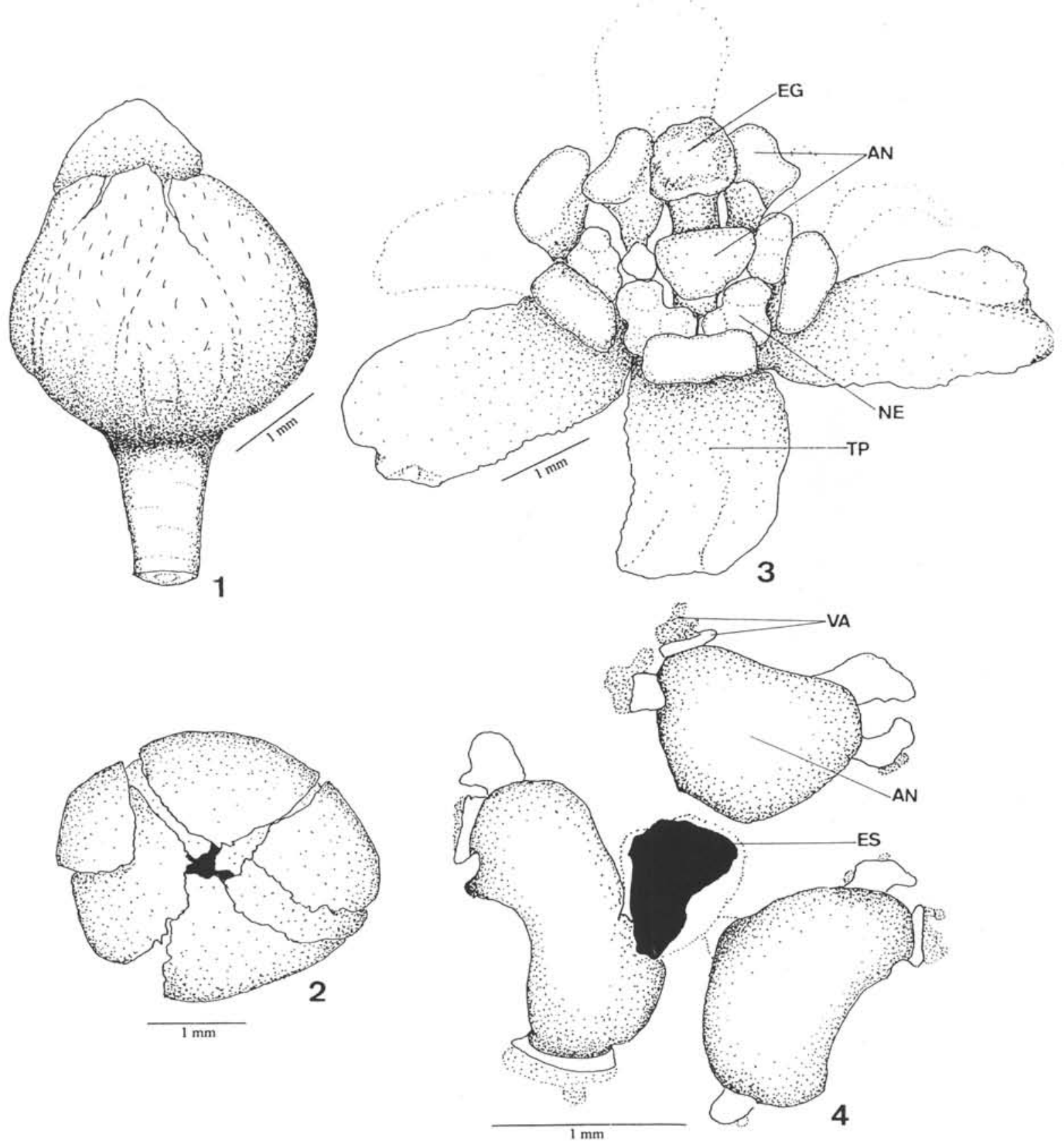

Figuras 1-4. Sequiência de antese e pós-antese: 1 . botão floral com apenas uma tépala afastada; 2 . botão com as outras tépalas afastando-se; 3 . flor aberta; 4. detalhe da flor com anteras abertas e estigma senescente. (AN-antera; EG-estigma; NE-nectário; TP-tépala; VA-valva e pólen). 

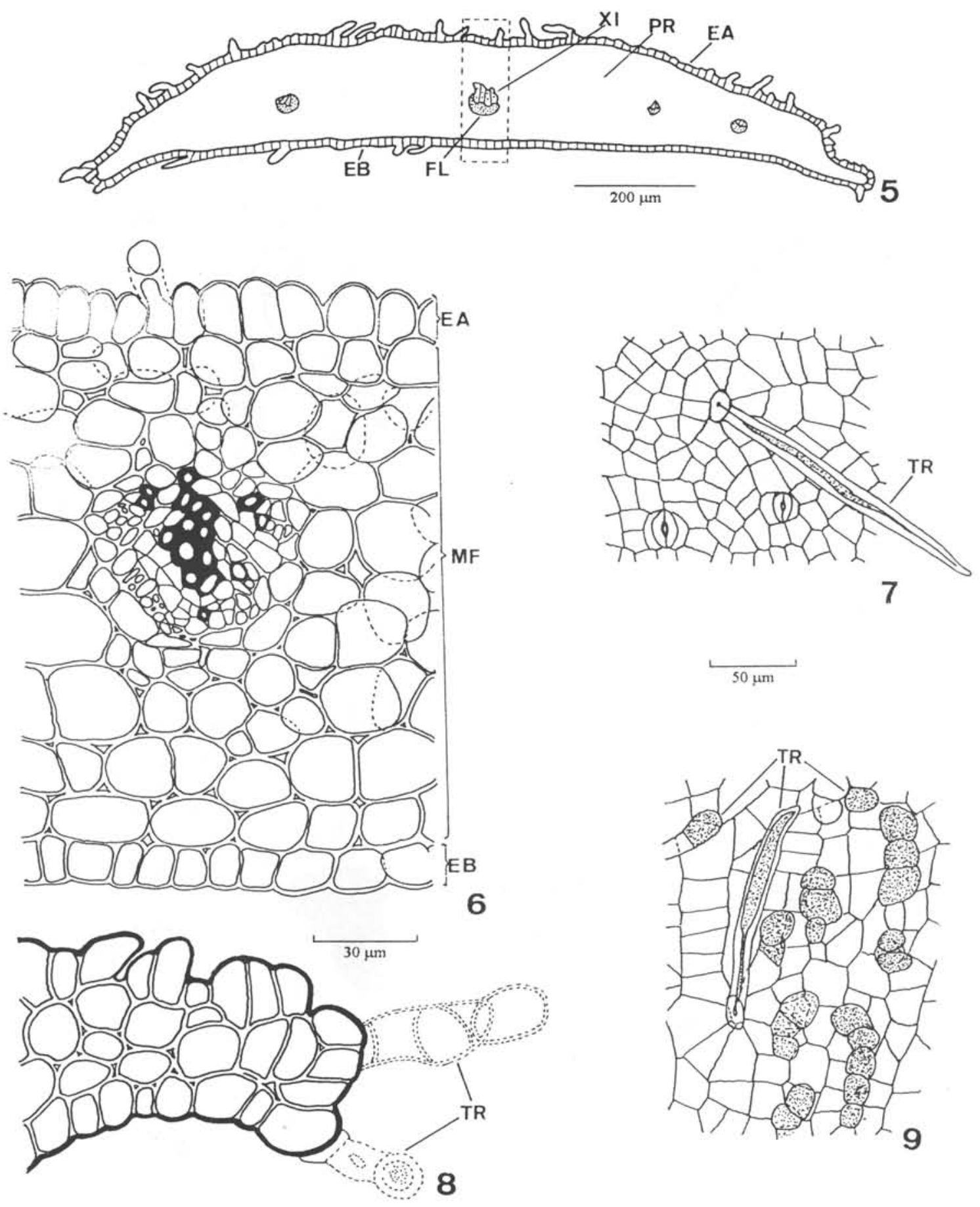

Figuras 5-9. Estrutura da tépala: 5. diagrama de corte transversal; 6. pormenor anatômico indicado na figura anterior; 7. Epiderme da face abaxial, em detalhe; 8 . pormenor anatômico do bordo; 9. Epiderme da face adaxial, em detalhe. (EAepiderme da face adaxial; EB-epiderme da face abaxial; FL-floema; MF-mesofilo; PR-parênquima; TR-tricoma; XIxilema), 

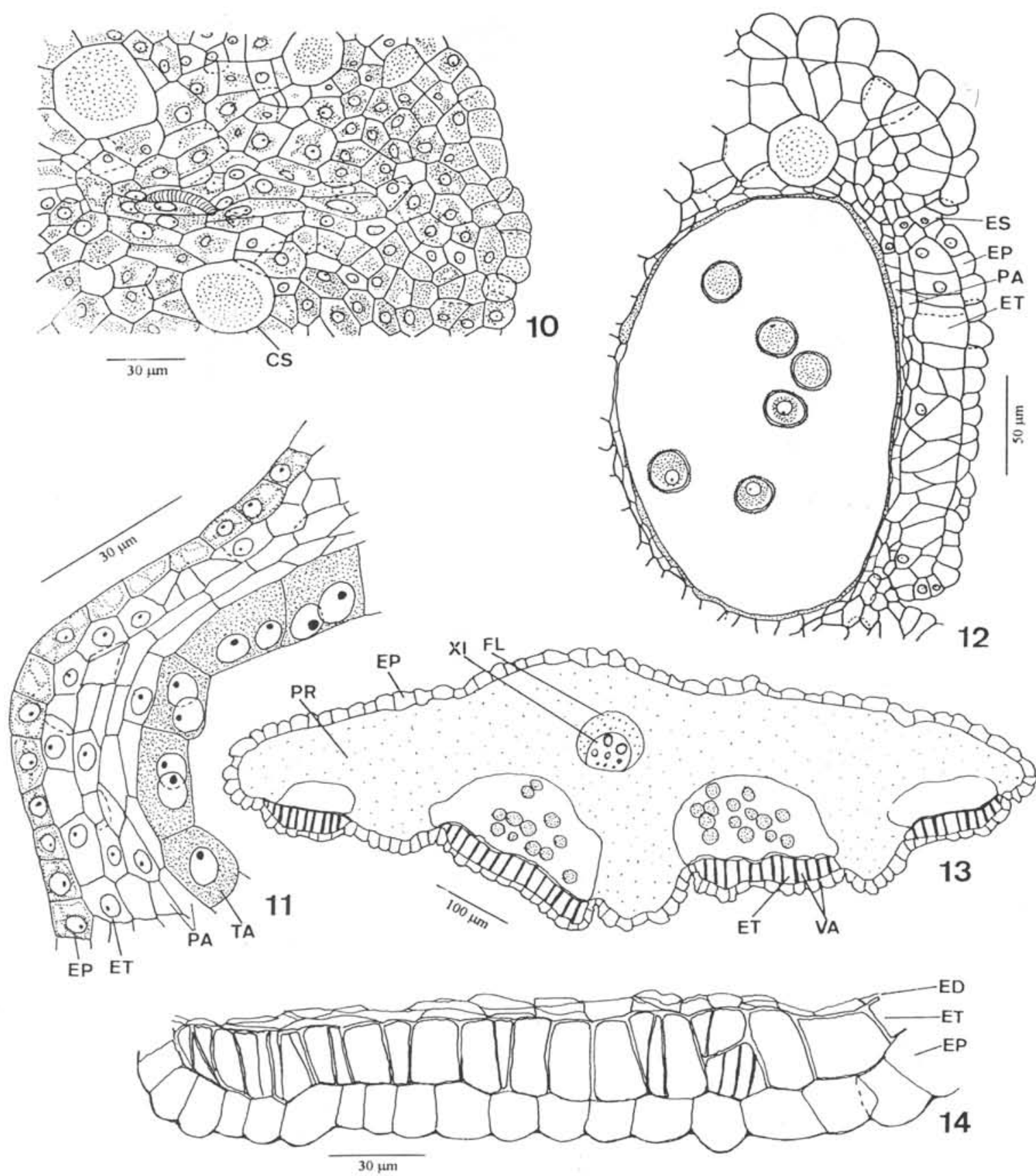

Figuras 10-14. Estrutura de nectário e antera: 10. pormenor anatômico do nectário; 11. pormenor anatômico da parede de antera jovem; 12. pormenor da antera em pré-deiscência; 13. diagrama de seção transversal da antera de flor aberta; 14. pormenor anatômico da valva mostrada na figura 13. (CS-célula secretora; ED-estratos desorganizados; EP-epiderme; ES-estômio; ET-endotécio; FL-floema; PA-estratos parietais; PR-parênquima; TA-tapete; VA-valva; XI-xilema). 


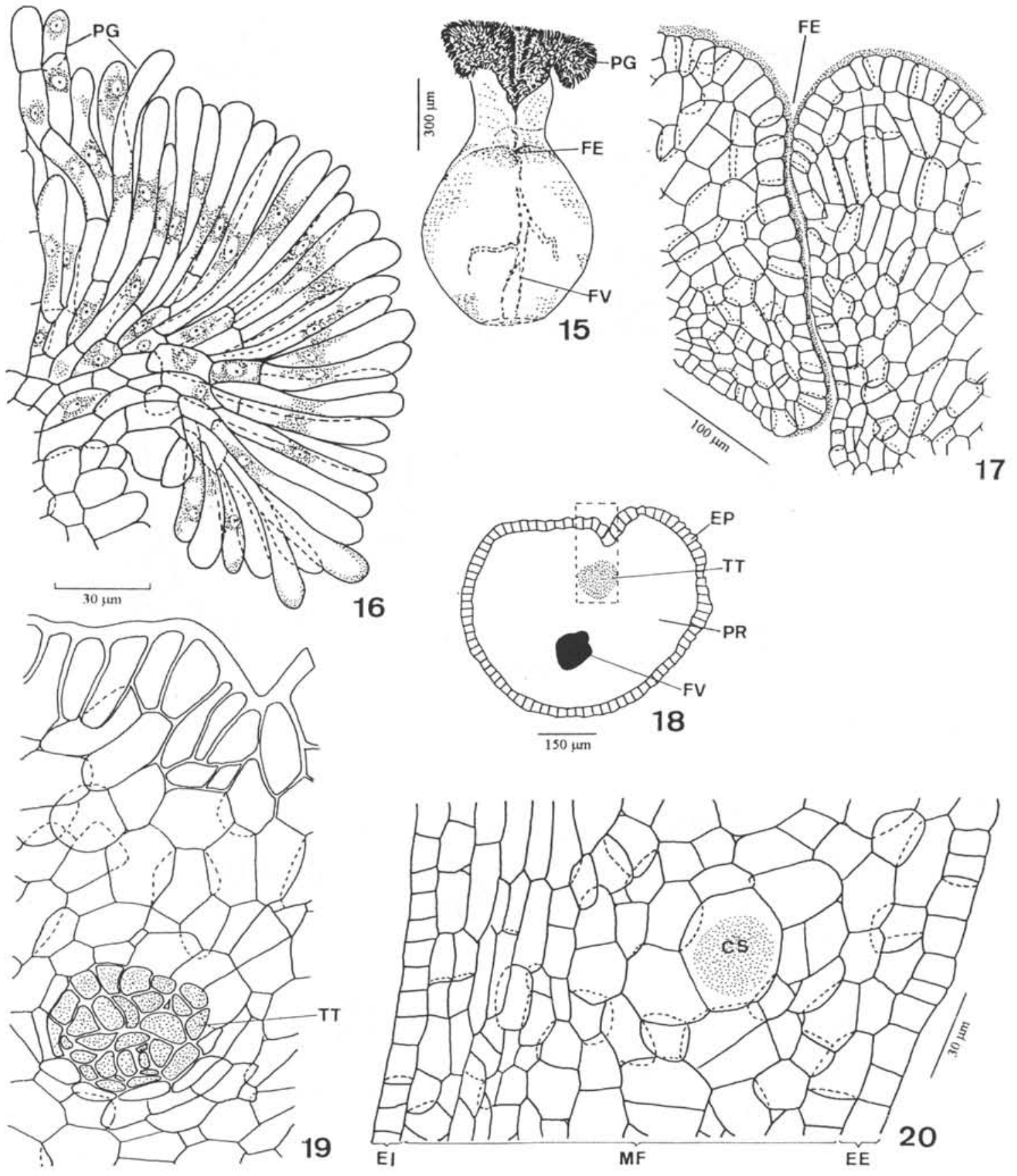

Figuras 15-20. Morfo-anatomia do gineceu: 15. gineceu em vista geral; 16. pormenor anatômico do estigma; 17. pormenor da parede do ovário, em corte longitudinal, mostrando a fenda; 18. diagrama do corte transversal do estilete; 19. pormenor anatômico indicado na figura anterior; 20. pormenor anatômico da parede do ovário mostrado na figura 21 (CS-célula secretora; EE-epiderme externa; EI-epiderme interna; EP-epiderme; FE-fenda; FV-feixe vascular; MF-mesofilo; PG-pêlos estigmáticos; PR-parênquima; TT-tecido transmissor). 

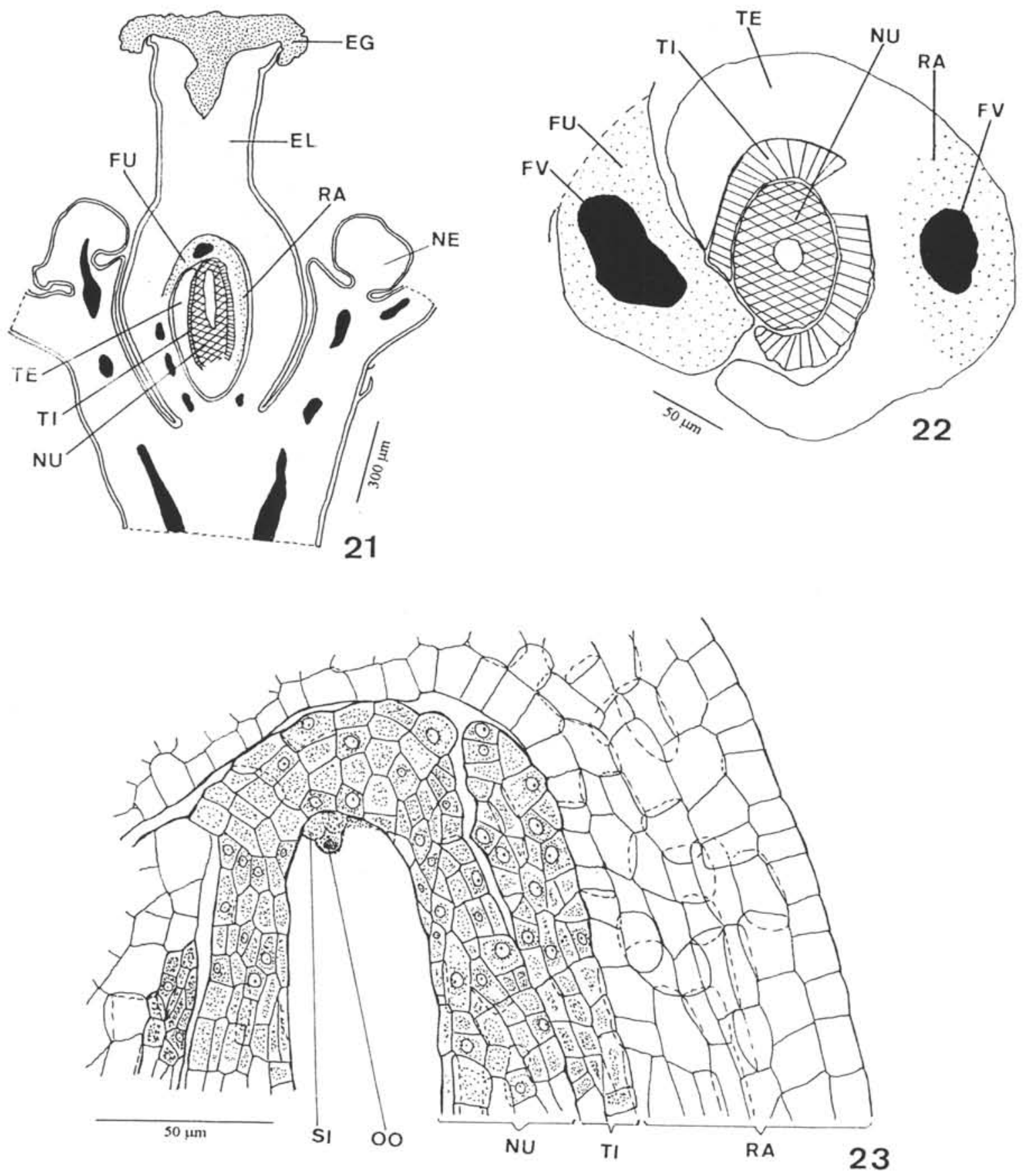

Figuras 21-23. Morfo-anatomia do gineceu: 21. diagrama do corte longitudinal de botão floral; 22. diagrama do rudimento seminal de botão floral secionado longitudinalmente; 23. pormenor anatômico da região micropilar do rudimento seminal, mostrado na figura 21. (EG-estigma; EL-estilete; FU-funículo, FV-feixe vascular; NE-nectário; NU-nucelo; OO-oosfera; RA-rafe; SI-sinérgide; TE-tegumeno externo; TI-tegumento interno). 
Kubitzski \& Kurz (1984), é considerada por Lloyd \& Webb (1986) como uma forma de redução na frequiência de autopolinização.

A possível protoginia constatada em $N$. megapotamica é considerada, por Faegri \& Pijl (1971), como mais efetiva do que a protandria como medida contra a autopolinização. Segundo esses autores a receptividade do estigma, mesmo poucas horas antes da abertura da antera, significa que qualquer pólen recebido será de outra flor, aumentando a probabilidade de polinização cruzada. Bertin \& Newman (1993) enfatizam, aliás, que é notável a incidência de protoginia em Magnoliidae e Hammamelidae, e de protandria nas Asteridae.

Os feixes vasculares das tépalas de $N$. megapotamica são pouco desenvolvidos e não apresentam esclerênquima, o que é comum no perianto de Angiospermas, segundo Fahn (1974). Aliás, Mauseth (1988) considera que as tépalas e os estames não necessitam desenvolver alta capacidade da função de condução, por serem estruturas delicadas e efêmeras.

Os nectários de $N$. megapotamica têm estrutura semelhante àquela apresentada por outras espécies de Lauraceae, incluindo, além da epiderme e parênquima secretor, células oleaginosas e feixe vascular rudimentar, onde há predomínio de floema. Fahn (1979) considera o feixe vascular do nectário o local de origem do néctar secretado. De acordo com esse autor, várias investigações de nectários de outras espécies mostraram que o pré-néctar move-se dos elementos crivados para o tecido parenquimático nectarífero, onde o néctar é secretado.

$\mathrm{O}$ número inicial de camadas médias formado numa antera, segundo Davis (1966), depende do tipo de formação dos estratos parietais, sendo duas camadas no tipo básico, uma única nos tipos dicotiledôneo e monocotiledôneo e nenhuma no reduzido. Por outro lado, essa mesma autora e Maheshwari (1950) registraram três ou mais camadas médias para algumas espécies ou famílias. A parede das valvas das anteras de $N$. megapotamica apresenta, também, três camadas médias; desse modo esta espécie pode ser acrescentada a este grupo de plantas de condição variável, quanto à estrutura dos estratos parietais da antera. A desorganização precoce das camadas médias é atribuída, por Davis (1966), à incapacidade de suas células sofrerem divisões anticlinais, não se ajustando, portanto, à multiplicação e expansão das células esporogênicas.

O número de carpelos do gineceu de espécies de Lauraceae é motivo de controvérsia na literatura botânica. Cronquist (1981) parece aceitar para a família um gineceu verdadeiramente monômero, mas Kostermans (1957) registra evidências de três, ou talvez seis, carpelos (gineceu pseudomonômero), embora este autor considere a existência de um recorte lateral no estigma de espécies de Lauraceae do gênero Ocotea como indício de um único carpelo.

A análise estrutural do gineceu de $N$. megapotamica revelou vários caracteres - a vascularização básica por dois feixes vasculares, a fenda microscópica na região superior do ovário como uma possível região sutural residual do carpelo e o recorte estigmático - como evidências claras de gineceu unicarpelar.

A fenda existente na região superior do ovário, se considerada como sutura residual, apresenta-se de forma diferente nas Lauraceae. $\mathrm{O}$ carpelo pode se apresentar parcialmente aberto, como em Ocotea puberula, ou completamente aberto em $N$. megapotamica, mesmo nos estádios mais tardios da antese. Aliás, Carlquist (1969) considera o carpelo aberto como caráter ontogenético e não como indicador seguro de primitividade. $\mathrm{O}$ referido autor afirma que os carpelos da maioria das Angiospermas são abertos durante o processo ontogenético e, em muitas plantas desse táxon, podem manter-se assim durante a antese.

$\mathrm{O}$ estigma de $N$. megapotamica parece se enquadrar bem no tipo seco, Grupo II (HeslopHarrinson \& Shivanna 1977), caracterizado por não produzir secreção abundante, superfície papilosa com papilas unisseriadas.

A observação de várias camadas celulares, 
localizadas entre a epiderme nucelar e o saco embrionário, no nucelo de $N$. megapotamica pode caracterizar o rudimento seminal desta espécie como crassinucelado. Esta possibilidade baseia-se em Maheshwari (1950), que considera o óvulo ou rudimento seminal crassinucelado como aquele que apresenta tecido parietal bem desenvolvido e a célula-mãe do megásporo separada da epiderme nucelar por uma ou várias camadas celulares, e na caracterização da família (Corner 1976). Todavia, Davis (1966) afirma que o uso dos termos crassinucelado e tenuinucelado têm gerado muita confusão na literatura botânica, introduzindo o tipo pseudocrassinucelado e sugerindo que se restrinja o termo crassinucelado aos óvulos ou rudimentos seminais em que a célula arquesporial se divide, formando uma célula parietal primária, que se divide ou não, e o termo pseudocrassinucelado, aos óvulos onde a célula parietal é formada e as células apicais da epiderme nucelar se dividem periclinalmente, originando a capa nucelar. No caso da espécie em estudo seria necessário o estudo ontogenético do desenvolvimento do nucelo para poder se afirmar se o rudimento seminal é crassinucelado ou pseudocrassinucelado.

\section{Referências bibliográficas}

Berlyn, G. P. \& Miksche, J. P. 1976. Botanical microtechnique and cytochemistry. The Iowa State University Press, Iowa.

Bertin, R. I. \& Newman, C. M. 1993. Dichogamy in Angiosperms. The Botanical Review 59(2): 112-152.

Carlquist, S. 1969. Toward acceptable evolutionary interpretations of floral anatomy. Phytomorphology 19(4): 332-362.

Corner, E. J. H. 1976. The seeds of dicotyledons. Cambridge University Press, Cambridge.

Cronquist, A. 1981. An integrated system of classification of flowering plants. Columbia University Press, New York.

Davis, G. L. 1966. Systematic embryology of the angiosperms. John Wiley \& Sons, New York.

Dnyansagar, V. R. 1958. Embryological studies in the Leguminosae. VIII. Acacia auriculaeformis A. Cunn., Adenanthera pavonina Linn., Calliandra hematocephala Hassk., and Calliandra grandiflora Benth. Lloydia 21(1): 1-25.
Endress, P. K. \& Igersheim, A. 1997. Gynoecium diversity and systematics of the Laurales. Botanical Journal of the Linnean Society 125(2): 93-168.

Faegri, K. \& Pijl, L. van der. 1971. The principles of pollination ecology. Pergamon Press, Oxford.

Fahn, A. 1974. Plant anatomy. Pergamon Press, Oxford.

Fahn, A. 1979. Ultrastructure of nectaries in relation to nectar secretion. American Journal of Botany 66(8): 977-985.

Gibson, P. J. \& Diggle, P. K. 1998. Flower development and male sterility in Ocotea tenera (Lauraceae): a gynodioecious tropical tree. International Journal of Plant Sciences 159(3): 405-417.

Herr, J. M. Jr. 1971. A new clearing-squash technique for the study of ovule development in Angiosperms. American Journal of Botany 58(8): 785-790.

Heslop-Harrinson, Y. \& Shivanna, K. R. 1977. The receptive surface on the angiosperm stigma. Annals of Botany 41: 1233-1258.

Johansen, D. A. 1940. Plant microtechnique. McGrawHill Book Company, New York.

Kostermans, A. J. G. H. 1957. Lauraceae. Reinwardtia 4(2): 193-256.

Kubitzki, K. \& Kurz, H. 1984. Synchronized dichogamy and dioecy in neotropical Lauraceae. Plant Systematics and Evolution 147: 253-266.

Kubitzki, K. \& Renner, S. 1982. Lauraceae I (Aniba and Aiouea). Flora Neotropica 5(31): 1-122.

Lloyd, D. G. \& Webb, C. J. 1986. The avoidance of interference between the presentation of pollen and stigmas in angiosperms. I- Dichogamy. New Zealand Journal of Botany 24: 135-162.

Maheshwari, P. 1950. An introduction to the embryology of angiosperms. Tata McGraw-Hill Publishing Company, New Delhi.

Mauseth, J. D. 1988. Plant anatomy. The Benjamin/ Cummings Publishing Company, California.

Rawlins, T. E. \& Takahashi, W. N. 1952. Technics of plant histochemistry and virology. The National Press, Millbrae.

Reitz, R.; Klein, R. M. \& Reis, A. 1983. Projeto madeira do Rio Grande do Sul. Sellowia 34/35: 1-525.

Rodrigues, R. R.; Gandolfi, S. \& Ribeiro, C. A. 1992. Revegetação das áreas degradadas da bacia do Ceveiro, Piracicaba (SP). Pp. 178-188. In: Anais do Simpósio Nacional sobre Recuperação de Áreas Degradadas. Curitiba 1992. Fundação de Pesquisas Florestais do Paraná, Curitiba. 